\title{
Ureterovesical Reimplantation in the Teaching Clinic of Urology and Andrology at HKM National Teaching Hospital of Cotonou: Indications, Techniques and Outcomes: About 36 Cases
}

\author{
Fred Hodonou, Josué Avakoudjo, Edoé Viyomé Sewa, Michel Agounkpe, Gilles Natchagande, \\ Jean Sossa, Magloire Yevi, Isidore Gandaho, Fouad Soumanou
}

Urology Department of HKM National Teaching Hospital, Cotonou, Benin

Email: martini_bj@yahoo.fr

How to cite this paper: Hodonou, F., Avakoudjo, J., Sewa, E.V., Agounkpe, M., Natchagande, G., Sossa, J., Yevi, M., Gandaho, I. and Soumanou, F. (2018) Ureterovesical Reimplantation in the Teaching Clinic of Urology and Andrology at HKM National Teaching Hospital of Cotonou: Indications, Techniques and Outcomes: About 36 Cases. Open Journal of Urology, 8, 214-222.

https://doi.org/10.4236/oju.2018.87024

Received: January 2, 2018

Accepted: July 23, 2018

Published: July 26, 2018

Copyright $\odot 2018$ by authors and Scientific Research Publishing Inc. This work is licensed under the Creative Commons Attribution International License (CC BY 4.0).

http://creativecommons.org/licenses/by/4.0/ (c) (i) Open Access

\begin{abstract}
Introduction: The presence of an obstacle in upper urinary tract, threatens kidneys and therapeutic arsenal includes an ureterovesical reimplantation especially in the case of lower ureteral obstacles. Ureterovesical reimplantation (UVR) techniques are numerous with each of its advantages and disadvantages. In order to review indications, techniques and the outcomes of the ureterovesical reimplantation in our context of work, we made this study. Material and Method: It was a retrospective, transversal, descriptive and analytic study conducted over a period of 10 years, in the department of urology University Hospital Center Hubert Koutoukou Maga of Cotonou. Patients over 15 years of age who have had a ureterovesical relocation had been included. Results: Thirty-six files were selected. Ureterovesical relocations accounted for $1.8 \%$ of surgical procedures. The ligatures iatrogenic ureters and vesico-vaginal fistulas were the most frequently involved in $33.4 \%$ and $27.8 \%$ respectively. The ureterovesical reimplantation was performed without anti-reflux plasty at $36.1 \%$ of patients. The technique of Politano-Leadbetter had been most accomplished, in $82.6 \%$ of the cases in which anti-reflux plasty had been made. Suites had been simple in $63.9 \%$ of patients. Postoperative complications were dominated by parietal suppurations and vesicocutaneous fistulas in respectively 6 and 4 patients. Conclusion: Ureterovesical reimplantations are interventions that require from the urologist a perfect knowledge given their complexity and the emergency context in which one may be led to practice them. They answer to general principles that reduce operative morbidity.
\end{abstract}




\section{Keywords}

Ureterovesical, Reimplantation, Indications, Techniques

\section{Introduction}

The presence of an obstacle regardless of its nature in upper urinary tract, threatens kidneys with a renal failure or the destruction of renal parenchyma. Therapeutic arsenal in this case includes a ureterovesical reimplantation especially in the case of lower ureteral obstacles.

Ureterovesical reimplantation (UVR) techniques are numerous with each of its advantages and disadvantages. No study had yet focused in the department on these techniques. In order to review indications, techniques and the outcomes of the ureterovesical reimplantation in our context of work, we have undertaken this study.

\section{Patients and Method}

This study was performed at the Teaching Clinic of Urology-Andrology of HKM Teaching Hospital of Cotonou in Benin.

It was retrospective and cross-sectional study over a period of 10 -years from 1st January 2006 to 31st December, 2015.

In this study, all patients aged over 15 years, hospitalized in the service and underwent ureterovesical reimplantation. We excluded patients whose files were incomplete or unusable.

Pre-established questionnaire was used for data collection from the hospitalization registry and operative reports. Epidemiological characteristics, the indications of UVR, the technique of UVR and the outcome data were collected. These useful and important parameters were analyzed. Anonymity of patients had been preserved in all cases.

\section{Results}

1) Epidemiological characteristic of the patients

Over a period of study, 30 patients underwent an UVR on a total of 2010 surgeries performed ( $1.8 \%$ cases). The mean age of patients was 39.6 years ranged from 16 to 36 years. Female were more represented with a sex ratio of 4/1.

Most of patients, $64.7 \%$ came from an urban and other a rural areas. They were distributed in all professional classes and traders (27.8\%) were the most represented, followed by public servants (19.4\%) and artisans (19.4\%).

2) Diagnosis and indications of the UVR

A lumbar pain witnessing a ureterorenal distension upstream of an obstacle is the most often reason of consultation. The leakage of urine per vagina is found in the history of 27 patients, 13 cases of hysterectomy, 8 cases of caesarean, 3 cases of bilharziosis, 2 cures of vesicovaginal fistula, 1 case of sigmoidectomy. It 
is particulary surgical histories. As shown in Table 1.

Among the paraclinical investigations, the renal function was abnormal with a rise of serum creatinine in $25 \%$ of patients. Urine analysis with antibiogram performed in 10 patients revealed a urinary infection in 8 patients, Escherichia coli was found in $75 \%$ of cases.

There were a total of 44 medical imaging examinations: 27 cases of ultrasonography of the urinary track, 10 of intravenous urography, 4 of computed tomography, 1 of anterograde pyeloureterography, 1 of cystoscopy and 1 plain abdominal radiography.

They have allowed finding out the conditions for which ureterovesical reimplantation was indicated as distributed in the following Table 2.

The following picture demonstrates the importance of ureterorenal distension (Figure 1).

3) Data relative to the surgical gesture

a) Qualification of the surgeon

Four patients out of $36(11.1 \%)$ underwent surgery by a urologist learner and other by a urologist.

b) Surgical routes

There are 13 cases of median incisions below the navel, 13 cases of hockey stick incision and 10 cases of Pfannenstiel.

c) Reimplantation technique

Analysis of surgical techniques revealed $36.1 \%$ cases of UVR without antireflux system. Building antireflux system according to Politano-Leadbetter is the

Table 1. Surgical histories.

\begin{tabular}{ccc}
\hline Surgical histories & Number & Frequency (\%) \\
\hline Hysterectomy & 13 & 48.1 \\
Ceasarien & 8 & 29.7 \\
Bilharziosis & 3 & 11.1 \\
VVF & 2 & 7.4 \\
Sigmoidectomy & 1 & 3.7 \\
Total & 27 & 100 \\
\hline
\end{tabular}

Table2. Ureterovesical reimplantation indications.

\begin{tabular}{ccc}
\hline Indications & Number & Frequency (\%) \\
\hline Iatrogenic ligature of ureter & 12 & 33.4 \\
Ureterovaginalfistula & 10 & 27.8 \\
Pelvis ureter stenosis & & 22.2 \\
Bladdertumor (partial cystectomy) & 8 & 8.3 \\
Ureterouterinefistula & 3 & 8.3 \\
Total & 3 & 100 \\
\hline
\end{tabular}

*Stenosis caused by bilharsiosis complicated by ureteral lithiasis. 


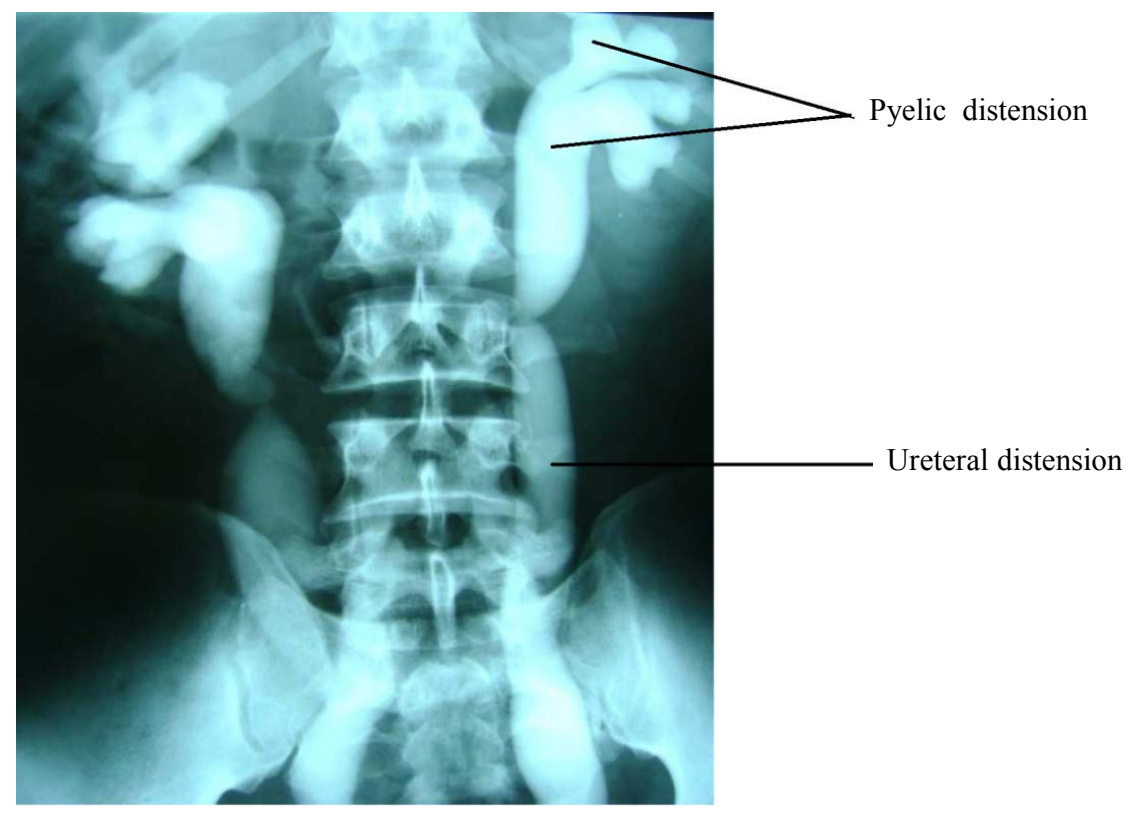

Figure 1. Intravenous urography showing bilateral ureterohydronephrosis grade 2 on bilateral stenosis of pelvic ureter.

most used ( $\mathrm{n}=19$ patients) followed by Cohen ( $\mathrm{n}=3$ patients) and of Hendren-Mollard ( $\mathrm{n}=1$ patient). Table 3 below shows indications or techniques used.

d) Complementary gestures

Complementary gestures carried out were a cure according to Boari-Kuss (1case), partial cystectomy (1case) and psoichal bladder ( 2 cases). Ureteral catheter tutor (92\% of cases), a urethrovesical catheter and a drainage catheter in contact with the ureteral hiatus were systematic in all patients.

e) Post operative follow up

They were simple in 23 patients. The post-operative complications found out are distributed in Figure 2. With bladder drainage and antibiotherapy, all these complications had evolved favorably in $20.3 \pm 3.2$ days without any else surgery. Post operative follow up was almost normal: a month after the discharge, plasma creatinine and urinary track ultrasonography were normal.

After 3 months, $62 \%$ of patients were lost of follow up. On case of hematuria noted after a partial cystectomy made for suspect tumoral progression. After 6 months, 3 cases of death had been identified, related to the bladder tumor.

\section{Discussion}

The major limitation of our study was its retrospective nature; this resulted in some missing data in patient records. Nevertheless, the majority of the parameters searched had been found, allowing us to carry out this study. Also, the retreat was not long enough and the check-ups requested to the patients did not make it possible to look for all the possible complications for lack of financial means of the patients who had to carry out the examinations. 
Table 3. Different processes of antireflux cure.

\begin{tabular}{ccc}
\hline Techniques & Number & Frequency (\%) \\
\hline Politano-Leadbetter & 19 & 82.6 \\
Cohen & 3 & 13 \\
Hendren-Mollard & 1 & 4.4 \\
Total & 23 & 100 \\
\hline
\end{tabular}

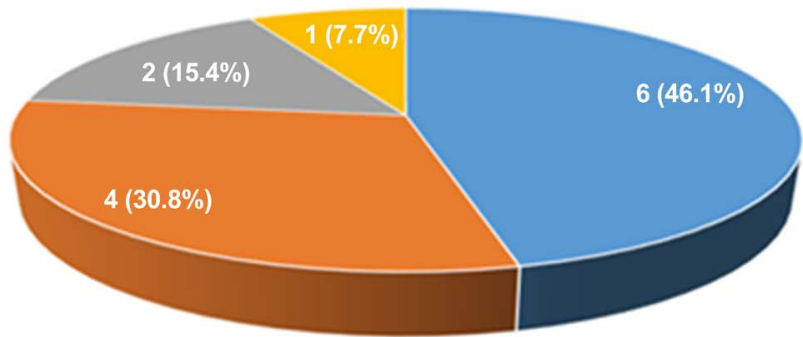

$=$ Parietal suppuration $=$ Urinary fistula $\quad=$ Lower urinary track infection $\quad=$ Acute pyelonephritis

Figure 2. Post-operative complications.

1) Indications

The frequency of this intervention, $1.8 \%$ of all surgical gestures in the service is low compared to $48 \%$ found in the work of Sissoko [1] at Bamako. Urogenital bilharziosis was the etiology at Bamako which is common in Mali [2]. In other hand at Cotonou in the service, the indications of the UVR are often related to the ureteral iatrogenics injuries. In fact, according to the many authors, these iatrogenics injuries result from pelvic surgery [3] [4] [5]. This pelvic surgery concerns especially the female. Hysterectomy and caesarean section are two types of pelvic surgery incriminated. Thus the study of the UVR shows the women as the more exposed to undergo this surgery: the sex ratio is $4 / 1$ in this work. This predominance of female and these two types of surgery are also found in the work of Kpatcha in Senegal [6], Bentaleb [5] and Karmouni [7].

Besides iatrogenic ureteral injuries as indications of the UVR, there were other indications not less rare: the urogenital bilharziosis in his ureteral localization particularly the end portion of ureters but also the bladder cancer with extension to ureteral meatus. The extension of bladder tumor to ureteral meatus threatens kidney function and leads therefore to the UVR indication. Onco-urology guidelines and the current place of the partial cystectomy in the management of urothelial bladder tumors [8] [9] light on the opportunity of a UVR especially when the margin of excision reached the ureteral meatus.

Among diagnostic equipments easily available, ultrasonography of urinary track, effective and repetitive exam, is the first exploration in front of features as lumbar pain and or oligoanuria in immediate postoperative. On 44 imaging performed, ultrasonography has been 27 times (75\%). It was the case in study of Diamoutene [10] in Mali. It is more used than computed tomography (CT) (4 
times out of 44 imaging performed) due to the high cost of CT. It allows locating the obstacle, determining the nature, and appreciating the structures surrounding. There is no use of CT in case of bilateral ureteral obstruction which is contraindicated cause of renal function impaired. The UVR was bilateral in $25 \%$ of patients in our study and 50\% in research work of Sidibe [11] in Mali.

The UVR as any other type of surgery requires a careful training of learner and a good choice of a techniques from specialist that he masters.

2) Techniques aspects and results

For Murtaza [12] in $70.2 \%$ of the cases and Rajasekar [13], iatrogenic ureteral injuries occur during the surgeries performed by learner. They were the main surgeons of $11.1 \%$ of the case.

Surgeon expertise is required particularly during this surgery which can be performed by opened route or laparotomy very attempted for young surgeons. Therefore, for Gambachidze, et al. [14] and other authors, open surgery remains the gold standard, laparotomy is used by experts.

Bloody or open way is only used in the service. Median incision under navel is often used. Others types of incision are encountered, particularly Hockey stick incision gathering anhemi Pfannenstiel and iliac incision.

Management by ureteral endoprothesis which permits the pyelovesical diversion of urine and ureterogenital fistula drainage, helps to avoid potential complications related to the surgery and other likely to UVR [15].

There are multiple and various techniques of UVR. The aim of those techniques is to prevent vesicoureteral urine reflux. Theoretically this aim is reached with the confection of antireflux system. It is based on a passage of terminal segment of ureter under the mucous which is linked to bladder. It is Politano-Leadbetter technique [16]. In other hand the connection of the ureter is direct, which means without under passage of mucous, that was the case of $36.1 \%$ of our patients.

This theoric insurance was questioned by many research works.

According to Stefanovie, et al. [17] it isn't necessary to perform antireflux system in adult because with or without antireflux, urinary fistula could occur. For Bastonand, et al. [18] the occurrence risk of vesicoureteral reflexive varies between $2 \%$ and $86 \%$ despite of the confection of antireflux system. Therefore direct UVR with antireflux technique of Lich-Gregoir, Sanei, et al. [19] revealed that the occurrence rate of vesicorenal reflux was the same in the two groups. $\mathrm{He}$ added that there was more stenosis of the new ureterovesical jonction and urinary fistula in the group with antireflux.

Taking into account issues from the comparison of research works, direct UVR is more used: $69.8 \%$ of patients in Sissoko study [1] in Mali. By the way we encountered new techniques: elephant proboscis technique by Sidibé [11] in Mali, "double-nippled ureteroneocystostomy" of Elmallah [20] in Egypt.

It is important to know that each surgeon uses a technique that gives better outcomes. To reduce ureteral stenosis incidence and urinary fistula, ureteral 
drainage was used both in our study and Hétet, et al. [21].

Infectious complications were observed in post-operative in our work. Surgery involved urinary track would be performed if urines are sterile or sterilized like Bruyère, et al. mentioned [22]. This rule can't be respected in emergency case likein ligature section of ureter (ceasarean section, hysterectomy non-scheduled etc.)

In the UVR, the urinary track fistula constitute a complication known and dreaded since they are potential leading causes of necrosis of implanted ureteral portion [23] and therefore a repetition of surgery. The bladder catheter and ureteral catheter allowed to dry these fistulas and to avoid the surgery repetition in all cases of our study.

In immediate post-operative the follow up of patient was based on plasma creatinine and ultrasonography data were normal. Within 3 months, $62 \%$ of patients were lost of follow up. The three cases of death within six months were related to the bladder tumor (Ideally computed tomography or intravenous urography is used for follow-up because ultrasonography evaluates badly the results, however ultrasonography gives an indirect evaluation especially for the upper urinary tract).

\section{Conclusion}

Ureterovesical reimplantations are certainly rare surgery in our context, which require a perfect knowledge on the part of the urologist, regarding the multiple indications and techniques. The indications of UVR in the Urology-Andrology Teaching Clinic of HKM Teaching hospital were dominated by the traumatic iatrogenic conditions of ureters and its consequences. Those conditions were widely due to gynecology and obstetric surgery namely hysterectomy and caesarean section. The ureterovesical reimplantations nowadays is improved by endoscopy and laparoscopy that allow to reduce significantly morbidity related to the surgery but the absence of these technical equipment in our service had not left any choice than open surgery. The post-operative complications were dominated by infections and urinary fistula.

\section{Conflicts of Interest}

The authors declare no conflicts of interest regarding the publication of this paper.

\section{References}

[1] Sissoko, S.A., Tembely, A. and Ouattara, K. (2005) UreteroneocystostomypostOperative Outcomes of in the Urologic Departement of Point G Hospital. Thèse Méd, Bamako, Mali, 52 p.

[2] Sangho, H., Dabo, A., Sangho, O., Diawara, A. and Doumbo, O. (2005)Prevalence and Perception of Schistosomiasis in Irrigated Rice Growing Area in Mali. Le Mali Medical, 20, 15-20.

[3] Bouya, P.A., Odzebe, A.W.S., Otiobanda, F.G., Itoua, C., Mahoungou-Guimbi, K., 
Banga, M.R., et al. (2011) Urological Complications of Gynaecologic Surgery. Progrès en Urologie, 21, 875-878. https://doi.org/10.1016/j.purol.2011.03.008

[4] Bobo Diallo, A., Sy, T., Oury Diallo, M.T., Bah, A.B., Touré, A., Bah, M.D., et al. (2015) Surgical Treatment of Urological Complications of Gynecological and Obstetric Surgeries at the University Hospital of Conakry Guinea. Open Journal of Urology, 5, 231-237.

[5] Bentaleb, H., Bensouda, A., Kabbaj, M., Karmouni, T., Tazi, K., El Khader, K., et al. (2007) Management of Iatrogenic Trauma of Ureter: About 24 Cases. African Journal of Urology, 13, 219-225.

[6] Kpatcha, T.M., Tengue, K., Anoukoum, T., Botcho, G., Sikpa, K.H., Fall, P.A., et al. (2014) Urological Complications of Pelvic Surgery at Teaching Hospital Aristide Le Dantec of Dakar. African Journal of Urology, 20, 206-210.

https://doi.org/10.1016/j.afju.2014.04.007

[7] Karmouni, T., Patard, J.J., Bensalah, K., Manunta, A., Guillé, F., Lobel, B., et al. (2011)Urological Management of Iatrogenic Trauma of Ureter. Progrès en Urologie, 11, 642-646.

[8] Rouprêt, M., Harmon, J.D., Sanderson, K.M., Barret, E., Cathelineau, X., Vallancien, G., et al. (2007) Laparoscopic Distal Ureterectomy and Anastomosis for Management of Low-Risk Upper Urinary Tract Transitional Cell Carcinoma: Preliminary Results. BJU International, 99, 623-627. https://doi.org/10.1111/j.1464-410X.2006.06688.x

[9] Iborra, F., Avances, C., Thuret, R. and Mottet, N. (2009) Current Role of Open Partial Cystectomy in the Treatment of Urothelial Bladder Tumors. Encycl Méd Chir (Elsevier Masson SAS, Paris), Techniques Chirurgicales-Urologie, 41-205.

[10] Diamoutene, A.M. (2007) Management of Ureteral Stenosis in Urological Department of Point G Teaching Hospital. Thèse Méd, Bamako, Mali, 95 p.

[11] Sidibé, A. and Ouattara, K. (2002) Ureteroneocystostomy Evaluation in Urological Department of Point G Teaching Hospital. Thèse Méd, Bamako, Mali, 72 p.

[12] Murtaza, B., Mahmood, A., Niaz, W.A., Akmal, M., Ahmad, H. and Saeed, S. (2012) Ureterovaginal Fistula-Etiological Factors and Outcome. Journal of the Pakistan Medical Association, 62, 999-1003.

[13] Rajasekar, D. and Hall, M. (1997) Urinary Tract Injuries during Obstetric Intervention. BJOG: An International Journal of Obstetrics \& Gynaecology, 104, 731-734. https://doi.org/10.1111/j.1471-0528.1997.tb11986.x

[14] Gambachidze, D., Phe, V., Drouin, S.J., Wolff, B., Parra, J., Mozer, P., et al. (2015) Aetiologies and Functional Outcomes after Ureteroneocystostomy in Adults: Litterature Review. Progrès en Urologie, 25, 683-691. https://doi.org/10.1016/j.purol.2015.06.007

[15] Al Otaibi, K., Barakat, A., El Darawany, H., Sheikh, A., Fadaak, K., Al Sowayan, O., et al. (2012) Minimally Invasive Treatment of Ureterovaginal Fistula: A Review and Report of a New Technique. Arab Journal of Urology, 10, 414-417. https://doi.org/10.1016/j.aju.2012.04.001

[16] Politano, V.A. and Leadbetter, W.F. (1958) An Operative Technique for the Correction of Vesicoureteral Reflux. The Journal of Urology, 79, 932-941. https://doi.org/10.1016/S0022-5347(17)66369-9

[17] Stefanovic, K.B., Bukurov, N.S. and Marinkovic, J.M. (1991) Non-Antireflux versus Antireflux Ureteroneocystostomy in Adults. British Journal of Urology, 67, 263-266. https://doi.org/10.1111/j.1464-410X.1991.tb15131.x

[18] Baston, C., Harza, M., Preda, A., Gener, I., Manea, I., Voinea, S., et al. (2014) Com- 
parative Urologic Complications of Ureteroneocystostomy in Kidney Transplantation: Transvesical Leadbetter-Politano versus Extravesical Lich-Gregoir Technique. Transplantation Proceedings, 46, 176-179.

https://doi.org/10.1016/j.transproceed.2013.12.003

[19] Sanei, B., Hashemi, M., Tabataei, A., Jafari, R. and Jafari, H.R. (2016) A Comparison between Two Kidney Transplant Ureteroneocystostomy Techniques: Full-Thickness Single Layer Anastomosis and Lich-Gregoir. Journal of Universal Surgery, 4, 56-59.

[20] Elmallah, E.S.M. (2009) Double-Nippled Ureteroneocystostomy: A Novel Surgical Technique in the Management of the Obstructed Dilated Ureter. African Journal of Urology, 15, 167-172. https://doi.org/10.1007/s12301-009-0030-7

[21] Hetet, J., Rigaud, J. and Karam, G. (2006) Should We Put a JJ Probe Systematically during a Kidney Transplant? Annales d' Urologie, 40, 241-246.

[22] Bruyère, F. and Faivred'Arcier, B. (2008) Open and Cœlioscopic Surgical Treatment of Vesicoureteral Reflux in Adult. Encycl Méd Chir (Elsevier Masson SAS, Paris), Techniques chirurgicales-Urologie, 41-133.

[23] Amri, H. (2012) Ureteroneocystostomy by Lich Gregoir Technique: Indications and Results. Thèse de Doctorat en Médecine $\mathrm{N}^{\circ} 109$, Université Cadi Ayyad, Marrakech Maroc, $136 \mathrm{p}$. 